\title{
APORTES HISTÓRICO E FILOSÓFICO PARA UMA ANÁLISE DOGMÁTICA DA INTERDEPENDÊNCIA ENTRE DIREITOS HUMANOS E DEMOCRACIA
}

\author{
Marcos Vieira de Lemos 1
}

\section{RESUMO}

Críticas às universalidades dos direitos humanos e democrática são capazes de por em xeque a relação entre eles. O presente artigo objetiva analisar a interdependência entre os institutos tendo como principal referencial o dogmático. Partindo do método analítico, observou-se com base nos Instrumentos Internacionais do Sistema Global sobre direitos humanos aprovados pelo Brasil, que à democracia, com exclusividade antes de 1993 e na maioria das vezes após isso, foi atribuído o papel negativo de suporte a limitações de direitos humanos. Após isso, confrontou-se essa constatação com breve caminho histórico e duas visões filosóficas sobre a democracia e os direitos humanos.

Palavras chaves: Democracia, Direitos Humanos, Interdependência, Dogmática,

\section{Tratados e Convenções.}

\section{ABSTRACT :}

Criticisms of the universality of human rights and democracycan put the relationship between them in jeopardy. This article aims at analyzing the interdependence of these institutions based mainly on a dogmatic approach. By using the analytical method and based on the International Instruments of the Global System on human rights approved by Brazil, one has observed that democracy received the negative attribute of supporting human rights limitations,exclusively before 1993 and most of the times after said year. Also, this finding has been confronted with a brief historical path and two philosophical views on democracy and human rights.

\footnotetext{
${ }^{1}$ Mestre em Direitos Humanos pela Universidade Federal de Goiás.
} 
Keywords: Democracy, Human Rights, Interdependence, Dogmatic, Treaties and Conventions.

\section{INTRODUÇÃO}

Muito poucos são os Estados que, assim como o Reino da Arábia Saudita², não se consideram democráticos, e outros há que inserem a democracia em seu próprio nome, sem que isso reflita sua verdadeira condição democrática, como é o caso da República Popular Democrática da Coréia do Norte, que detém isoladamente nos últimos 10 anos, a última posição no quesito democrático, dentre 167 países avaliados pelo "The Economist Intelligence Unit's Democracy Index" ${ }^{3}$, que leva em consideração as liberdades civis, o processo eleitoral e pluralismo, o funcionamento do governo, participação política e cultura política dentro do Estado avaliado.

Por outro lado, o Regime Democrático tem sido considerado como ambiente (LEMOS, 2008) - por vezes único ambiente - propício para o desenvolvimento e mesmo surgimento dos direitos humanos. Isso se deve, em boa parte, à positivação do binômio direitos humanos - democracia, presente em grande número de Instrumentos Internacionais de Proteção dos direitos humanos. Deve-se também ao fato de que, mesmo aqueles (ex vi : COELHO; PEDRA, 2010) que reconhecem e apontam que o caminho histórico dos direitos humanos e da democracia não foi coincidente e que tiveram (ou terão) ${ }^{4}$ momentos distintos de efetivação, filosoficamente, não se afastam da importância de um discurso efetivamente democrático acerca dos Direitos do Homem.

No entanto, muitas e poderosas são as críticas a pretensões universalistas ${ }^{5}$ de valores apenas locais, e nada há a princípio, que garanta que a democracia (sobretudo se pensada apenas no sistema político) e os próprios direitos humanos não passem de um

${ }^{2}$ A Arábia Saudita, mesmo após a Primavera árabe, mantêm-se como uma Monarquia Absolutista Teocrática, onde o poder do monarca é limitado apenas pela Sharia (Lei teocrática islâmica), fazendo o Alcorão, as vezes de Constituição nesse país. De acordo com o The Economist Intelligence Unit's Democracy Index nos últimos 10 anos, deteve sempre um dos 8 piores índices democráticos entre 167 países considerados .

3 EIU Democracy Index 2018 - Infographics - The Economist, disponível em https://infographics.economist.com/2018/DemocracyIndex/ , acesso em 06/03/2019.

4 Os autores apontam a matriz liberal pós-revolucionária do séc. XIX como referência de (in)efetivação do projeto democrático, distanciando-a da efetivação dos direitos humanos que continua inacabada. Elucidam, que na verdade, o liberalismo funcionou como um limitador de efetivação tanto do projeto democrático, quanto do projeto dos Direitos Humanos.

${ }^{5}$ O $1^{\circ}$ Considerando da Declaração de Viena de 1993 considera expressamente a Democracia como uma aspiração universal. 
"localismo globalizado", tal como definido por Boaventura de Sousa Santos ${ }^{6}$, operando como "instrumento do choque de civilizações tal como o concebe Samuel Huntington (1993), ou seja, como arma do Ocidente contra o resto do mundo " (SANTOS, 1997).

Nesse cenário, surgem ainda as críticas das críticas e deve-se reconhecer que os recentes eventos da Revolta Árabe engrossaram as linhas dos que defendem o universalismo de valores democráticos e humanistas (ROCHA, 2011).

Nesse contexto, pretende inserir-se o presente trabalho que se propõe a investigar as relações entre democracia e direitos humanos, principalmente sob o enfoque dogmático, mas dedicando-se ainda, brevemente, aos enfoques histórico e filosófico, como segue:

\section{a) enfoque dogmático (seção II)}

Concentrando-se os esforços na identificação de disposições constantes das mais importantes Declarações de direitos humanos e dos mais relevantes Tratados Internacionais de Proteção de Direitos Humanos, respectivamente aprovadas e ratificados pelo Brasil, conforme relacionados por Felippe (1996), que estabeleçam expressamente uma relação entre democracia e direitos humanos. Os instrumentos analisados foram os constantes do compendio disponibilizado pela Procuradoria do Estado de São Paulo e prefaciado pelo professor Antônio Augusto Cançado Trindade;

b) enfoque histórico (seção III)

Onde o objetivo será o de tentar acompanhar, minimamente, em um recorte temporal, o percurso dos institutos em exame, principalmente tentando identificar-lhes a origem histórica e pontos de aproximação ou simultânea inflexão;

c) enfoque filosófico (seção IV)

Nesta perspectiva, a proposta de abordagem partiu do pensamento predominante sobre as relações entre direitos humanos e democracia constante de duas obras de referência: $O$ que é a Democracia? de Alain Touraine, e A Democracia. de

\footnotetext{
${ }^{6}$ O autor em "Por uma concepção multicultural de Direitos Humanos" de 1997, traz o conceito de "localismo globalizado" como uma forma de globalização hegemônica, especialidade dos países que detêm o controle econômico e que por isso são capazes de implantar, mundialmente, valores, que a princípio seriam apenas locais. O hambúrguer é um bom exemplo.
} 
Hans Kelsen. Como nos precedentes, o foco foi o de observar como os institutos, predominantemente, se relacionam na visão dos autores.

\section{PERSPECTIVA DOGMÁTICA}

Para além da afirmação que fizemos acima, de que a democracia tem sido considerada como o ambiente propício para o desenvolvimento e mesmo surgimento dos direitos humanos, o respeito aos direitos humanos (internamente constitucionalizados como Direitos Fundamentais) e as próprias Declarações de Direitos do Homem e do Cidadão são freqüentemente, encarados como fundamento das democracias modernas (OLIVEIRA, 2007), pois estas, em última análise, têm por objetivo realizar valores inerentes a esses direitos. Eis aí uma visão extremamente simplificada da interdependência entre os conceitos de democracia e respeito aos direitos humanos, reconhecida pela Declaração de Viena de 1993, que ainda estipula o reforço mútuo desses conceitos.

Cumpre, no entanto, com o objetivo de estudar essa relação de interdependência, através de um assumido compromisso com o método analítico, proposto neste tópico e principal objetivo deste trabalho, identificar os dispositivos relativos à democracia, constantes dos Instrumentos Internacionais que versem sobre Direitos Humanos. Como limitador de conteúdo, selecionamos tão somente as disposições que expressamente refiram-se à democracia e tão somente dos Instrumentos Internacionais aprovados ou ratificados ${ }^{7}$ pelo Brasil. Com efeito, foram analisados dezessete Instrumentos Internacionais ${ }^{8}$ :

\footnotetext{
${ }^{7}$ Utiliza-se o termo "aprovados" para as Declarações e "ratificados" para os Tratados.

${ }^{8}$ Conforme classificação proposta pela Procuradoria Geral do Estado de São Paulo, apresentada por Márcio Sotelo Felippe (op. cit):

I. Declarações de Direitos Humanos aprovadas pelo Brasil

a) Sistema Global

Declaração Universal dos Direitos Humanos - 1948

Declaração do Direito ao Desenvolvimento - 1986

Declaração e Programa de Ação de Viena -1993

Declaração de Pequim - 1995

b) Sistema Regional Interamericano

Declaração Americana dos Direitos e Deveres do Homem - 1948

II. Tratados Internacionais de Proteção de Direitos Humanos ratificados pelo Brasil

a) Sistema Global

Preceitos da Carta das Nações Unidas - 1945

Convenção contra o Genocídio - 1949
} 
Dos instrumentos analisados, em apenas em oito identificamos disposições expressas relacionadas à democracia. Foram eles:

1. Declarações de direitos humanos aprovadas pelo Brasil que expressamente, de alguma maneira, referem-se à democracia

a) Sistema Global

1.1 Declaração Universal dos Direitos Humanos - 1948

1.2 Declaração e Programa de Ação de Viena -1993

1.3 Declaração de Pequim - 1995

b) Sistema Regional Interamericano

1.4 Declaração Americana dos Direitos e Deveres do Homem - 1948

II. Tratados Internacionais de Proteção de Direitos Humanos ratificados pelo Brasil que expressamente, de alguma maneira, referem-se à Democracia

a) Sistema Global

1.5 Pacto Internacional dos Direitos Civis e Políticos - 1966

1.6 Pacto Internacional dos Direitos Econômicos, Sociais e Culturais - 1966

1.7 Convenção sobre os Direitos da Criança - 1989

b) Sistema Regional Interamericano

1.8 Convenção Americana sobre Direitos Humanos - 1969

Nesses oito instrumentos identificamos dezenove dispositivos que expressa e diretamente, em alguma medida, relacionam democracia e direitos humanos. Esses dispositivos compõem o Anexo I deste Artigo e foram agrupados no quadro constante do Anexo II, onde a última coluna corresponde à síntese da disposição referida no dispositivo

Convenção relativa ao Estatuto dos Refugiados - 1951

Protocolo sobre o Estatuto dos Refugiados - 1966

Pacto Internacional dos Direitos Civis e Políticos - 1966

Pacto Internacional dos Direitos Econômicos, Sociais e Culturais - 1966

Convenção sobre a Eliminação de todas as formas de Discriminação Racial - 1968

Convenção sobre a Eliminação de todas as formas de Discriminação contra a Mulher - 1984

Convenção contra a Tortura e outros Tratamentos ou Penas Cruéis, Desumanos ou Degradantes 1984

Convenção sobre os Direitos da Criança - 1989

b) Sistema Regional Interamericano

Convenção Americana sobre Direitos Humanos - 1969

Convenção Interamericana para Prevenir e Punir a Tortura - 1985

Convenção Interamericana para Prevenir, Punir e Erradicar a Violência contra a Mulher - 1994 
evidenciado. Nesta coluna, adotamos a sigla "RIPD", correspondente ao que identificamos nos instrumentos em análise como dispositivos que se referem a "Restrições Indispensáveis Para a Democracia" e refere-se ao fato de que o conteúdo da norma, contida no Anexo I deste estudo, literalmente corresponde a uma restrição de direitos, feita apenas na medida do indispensável em uma sociedade democrática. Na verdade, funcionam como restrições indispensáveis à democracia e feitas pela democracia, pois sempre dependentes de lei.

O quadro do Anexo II evidencia que em onze das dezenove vezes (aproximadamente 60\%) em que a democracia é mencionada em Instrumentos Internacionais aprovados pelo Brasil, ela é mencionada como parte do suporte autorizativo da restrição específica de algum Direito Humano. Nesses dispositivos a democracia desempenha, portanto, um papel negativo, mas essencial, frente aos direitos. A essencialidade dessa função democrática, internacionalmente reconhecida, decorre da necessidade de conformação dos direitos pelos legisladores nacionais, visto que seus exercícios (dos direitos) podem dar ensejo, muitas vezes, a uma série de conflitos com outros direitos igualmente valorizados.

O quadro também permite observar uma curiosidade, que acreditamos merecer maiores investigações, não comportadas pelo estreito propósito deste Artigo: antes da derrocada dos Estados Socialistas em 1989, no âmbito do Sistema Global, à democracia só foi expressamente atribuída, pelos Instrumentos Internacionais, essa função negativa de limitadora de direitos. A democracia só foi considerada uma aspiração universal, nesse sistema, em 1993, na Declaração de Viena, que também lhe estabelece como fundamento a liberdade, no sentido de autodeterminação. Além disso, a Declaração (de Viena) coloca a democracia em uma situação de interdependência e reforço mútuo com os direitos humanos e estipula que a comunidade internacional deve apoiar seu fortalecimento e promoção, bem como deve apoiar aos países subdesenvolvidos em sua transição para a democracia.

expressão deste desejo da comunidade internacional pela democratização dos países subdesenvolvidos, pressupunha a aspiração universal de democracia e essas declarações foram feitas concomitantemente em 1993.

No contexto ora estudado, destacam-se na Declaração de 1993, a declaração de aspiração universal da democracia, colocando-a junto com os direitos humanos, como dois valores de aspiração universalista e talvez, justamente por isso, a Declaração os coloca em situação de interdependência e reforço mútuo. 
Por outro lado, no âmbito do Sistema Regional Interamericano, já em 1969, houve previsões outras sobre a democracia, que não exclusivamente aquelas que lhe atribuía a função conformadora de direitos: foi reafirmado o propósito de consolidar no continente americano, dentro do quadro das instituições democráticas, um regime de liberdade pessoal e de justiça social, fundado no respeito aos direitos humanos essenciais. Também foi previsto que nenhuma disposição da Convenção Americana de 1969 poderia ser interpretada no sentido de excluir outros direitos e garantias inerentes ao ser humano ou que decorressem da forma democrática representativa de governo. Trata-se do reconhecimento expresso de que direitos e garantias do ser humano, não expressados, podem decorrer da forma democrática representativa de governo.

É interessante observar que em sentido oposto à maioria das previsões encontradas sobre democracia nos instrumentos analisados, que lhe atribuíam função de conformadora de direitos, a previsão contida no artigo 29. c) da Convenção Americana de Direitos Humanos de 1969, reconhece, para a democracia, um potencial gerador de direitos, um papel positivo, normogenético, que no direito interno costuma repousar sobre os princípios, fazendo-lhes funcionar como vetores de interpretação normativa, ou mesmo como geradores de novas normas que lhe aumentem a aptidão para a concreção.

\section{PERSPECTIVA HISTÓRICA}

Inicialmente anota-se que a pluralidade de conceitos modernos sobre democracia e de interpretações de tais conceitos varia ainda tanto na atualidade, como variou no curso da história democrática.

Não existe, pois, um conceito unificado e completo de democracia, do mesmo modo que o modelo democrático não deve ser entendido como um modelo perfeito e acabado. As diferentes conceptualizações do termo e as disparidades encontradas na sua materialização prática são resultado dos desenvolvimentos político-sociais e económicos decorrentes da história e das conjunturas nacional e global, uma vez que o próprio curso do tempo moldou os regimes democráticos existentes, na procura de novas soluções e alternativas para os inúmeros desafios e constantes mutações do sistema internacional.(SOUSA, 2006) 
Essa amplitude e variância do conceito de democracia tornam-se mesmo um obstáculo, na tentativa de aproximar ou não sua evolução histórica com a dos direitos humanos, pois quando se varia o conceito de democracia, varia também a forma como esta se relaciona com os direitos humanos. Essa variância por outro lado, permite perceber, que quando e onde os direitos da vez, deixaram de ser os civis e políticos e passaram a ser os sociais, o discurso democrático soltou as mãos do liberalismo e deu-se de braços com o socialismo. E quando se acreditou que as reivindicações sociais só podiam ser atendidas no âmbito do Estado-nação e por um líder ditador, de poder absoluto, a democracia desviou-se de sua origem e caminho lógico, convertendo-se em “democracia totalitária” (SOUSA, 2006).

De toda sorte, a dificuldade de acompanhamento das trajetórias ou as percepções de inflexões concomitantes nelas, não impedem a certeza de que os caminhos históricos dos direitos humanos e da democracia não foram coincidentes (COELHO; PEDRA, 2010), estando separados na origem, pelo menos em uma concepção rigorosa de direitos humanos $^{9}$, por mais de 2.400 anos de história.

É lugar comum que somente a partir do século XVIII, com as Declarações americana e francesa, podemos seguramente, falar em direitos humanos. Por outro lado, a primeira experiência democrática de que se tem notícia histórica, embora incompleta, por dar voz política apenas a uma pequena parte da população, remonta ao século V a.C., em Atenas, sendo que já no século VI a. C. ocorre a criação das primeiras instituições democráticas (COMPARATO, 2010). Contudo, em alguma medida, já nessa época, é possível vislumbrar um primeiro encontro entre a democracia e os direitos humanos, pois a primeira funcionou como uma limitação institucional ao poder de governo.

Efetivamente, na vida política ateniense, por mais de dois séculos (de 501 a 338 a. C.), o poder dos governantes foi estritamente limitado, não apenas pela soberania das leis, mas também pelo jogo complexo de um conjunto de instituições de cidadania ativa, pelas quais o povo, pela primeira vez na História, governou-se a si mesmo. (COMPARATO, 2010, p. 55).

E nesse contexto, não se deve esquecer que o que fez do século XVIII o marco inaugural incontestável dos direitos humanos, foi a limitação do poder estatal.

\footnotetext{
${ }^{9}$ Que os considera como tais, somente após as Declarações do século XVIII.
} 
Encarando-se os fatos dessa forma, é possível defender-se, que em alguma medida, a democracia e os direitos humanos tiveram uma origem comum, não esquecendo-se, é claro, que na Grécia antiga inexistia a noção de liberdade pessoal, com a aceitação da servidão como uma instituição perfeitamente integrada ao modo de vida social, motivo pelo qual, apenas em "alguma medida" podemos cogitar de um reconhecimento de direitos humanos naquela época.

Mas seja como for, essa aproximação inicial durou pouco, pois a democracia ateniense foi devastada pela expansão do império de Alexandre, o Grande, seguida pelo início da idade média (COMPARATO, 2010). Esses ideais ocidentais (democracia e direitos humanos), então, só haveriam de se reencontrar no ideário iluminista da Revolução Francesa (COELHO; PEDRA, 2010).

Há de se apontar, entretanto, que o ressurgimento democrático nessa época, se deu em moldes muito distintos dos da democracia grega, que mais acima apontamos. Esta última era exercida diretamente por "pequenos camponeses e artesãos, ou seja, por grupos de baixo poder econômico". Em oposição, a democracia que ressurgiu na França e na América do Norte no século XVIII, era exercida por representantes das Oligarquias (COMPARATO, 2010, p.63) ${ }^{10}$. E é no mínimo questionável que uma estrutura de poder possa estar a serviço das oligarquias e ao mesmo tempo dos direitos humanos.

É nesse sentido, que Coelho e Pedra apontam o liberalismo, como uma forma limitadora tanto da democracia quanto dos direitos humanos, e ao mesmo tempo separadora "dessas duas reivindicações da racionalidade social ocidental" no que se refere aos seus momentos de efetivação, pois o liberalismo impõe à democracia e aos direitos humanos distintos graus de efetivação (COELHO; PEDRA, 2010).

A democracia, ressurgida nas Revoluções Francesa e Americana, foi impulsionada por outra revolução, a industrial, a partir de fins do século XVIII, mas na Europa industrializada, de maior concentração urbana e de crescentes problemas sociais,

${ }^{10} \mathrm{O}$ autor elucida que a democracia moderna "foi a fórmula política encontrada pela burguesia para extinguir os antigos privilégios dos dois principais estamentos do ancien regime - o clero e a nobreza - e tornar o governo responsável perante a classe burguesa". No mesmo sentido, mas em relação à América-Latina, Borges (2015) aponta que os modelos constitucionais adotados pelo países latino-americanos orbitavam entre o modelo republicano estadunidense e modelos de monarquias constitucionais européias, mas sempre com estrutura de poder do liberalismo e que as constituições assim formatadas serviam aos interesses das oligarquias rurais ou de elites comerciais exportadoras. 
florescem no século XIX ideais socialistas, que convertem a democracia liberal (governo do povo) da Revolução Francesa em uma democracia de cunho proletário, baseado na igualdade social (governo para o povo), esse novo conceito de democracia popular estará na Europa após a Segunda Guerra, mas já antes desta guerra, havia assumido suas formas totalitárias (fascismo e comunismo), verdadeira antítese da democracia, pelo menos na concepção liberal dela (SOUSA, 2006).

Os direitos humanos, paralelamente, após suas vitórias de Primeira Geração, que superaram os estamentos sociais - que sufocavam qualquer tentativa de igualdade civil e política até o último quarto do século XVIII - voltaram-se para a nova divisão social que se formava (proprietários, ricos x trabalhadores, pobres) buscando, um século depois, estabelecer uma nova igualdade para a desigualdade criada pela ainda nova igualdade de direitos individuais - era o nascimento dos direitos sociais, ditos humanos de segunda geração, e com eles, do próprio Estado Social (BENEVIDES, 2014). O fracasso do Estado Liberal de Direito no século XIX, foi explicado, em termos de Direitos Fundamentais do Homem, como decorrência da inefetivação destes, que foram "convertidos em meros discursos legitimadores, com pouca ou quase nenhuma capacidade performativa", sendo inclusive preteridos, por leis, que supostamente eram legitimadas por eles, mas que na verdade distorciam tanto a ordem hierárquica (COELHO, 2015), quanto o próprio conteúdo dos valores tutelados.

Após estarem sob as limitações do liberalismo do século XIX, os direitos humanos e a democracia se reaproximaram na ascensão do socialismo e demais formas de crítica ao liberalismo (COELHO, 2012) ${ }^{11}$, pelo menos até que estas assumissem as formas autoritárias e totalitárias, cujo fortalecimento na década de 30, levou à Segunda Grande Guerra Mundial.

Nesse contexto, é oportuno apontar que o universalismo dos direitos humanos faz parte das declarações do século XVIII, mas foi apenas com os horrores da Segunda Guerra, que para além da teoria "ficou claramente demonstrado que os direitos do homem deveriam transcender os limites constitucionais de cada Estado para serem tutelados pelo Direito Internacional” (LEMOS, op. cit., p. 185) de fato, consideramos que os horrores da Segunda Guerra, funcionam como auto-evidência da necessidade de universalização dos

${ }^{11} \mathrm{O}$ autor ainda aponta que no período do pós-guerra rebrota a figura do Estado Social de Direito, sendo que " o neoliberalismo e a social-democracia, e. g., têm, cada qual o seu discurso próprio sobre direitos humanos, e viram surgir outros, tal como o dos ambientalistas (a ideologia verde) e o dos ideólogos da sustentabilidade." 
direitos humanos. Cabe então perquirir, no objetivo de analisar as trajetórias históricas dos direitos humanos e da democracia, não se esta também tem pretensão universalista declarada $^{12}$, mas sim, se para além das previsões da normativa internacional, há demonstrações históricas, bem como suporte filosófico, sobre a necessidade de uma universalização da democracia.

Reconhecemos de antemão, que a transcendência da democracia, ainda mais comprovada historicamente, extrapola as possibilidades de esforço deste trabalho, mas apontamos que a recente, imprevista e inesperada democratização do Magreb (ou pelo menos tentativa de), por motivos ${ }^{13}$ que estão cada vez mais entre nós, e na sociedade contemporânea são auto-replicantes, talvez tenha o potencial de servir como uma espécie de fiel da balança para se avaliar a consideração do autor do livro "Magreb, a democracia impossível?", Pierre Vermeren para quem "a ideia de que a democracia não é para o mundo árabe remete a preconceitos coloniais" (VERMEREN, apud Bouderbala, 2011).

\section{PERSPECTIVA FILOSÓFICA}

A fim de encontrar a relação de interdependência entre democracia e direitos humanos na obra "A Democracia” de Kelsen, partimos da crítica que o autor faz à democracia de cunho proletário, referida na seção anterior. A democracia social, após ser definida como “ uma ordem social que garantiria aos indivíduos não só uma participação formalmente igual na formação da vontade coletiva, mas também em uma quantidade igual de riquezas", foi rechaçada por defender o valor igualdade, e não o valor que verdadeiramente define democracia: liberdade (KELSEN, 2000, p. 99). Não que o autor não reconheça o valor "igualdade" presente na ideologia democrática, mas o reconhece, apenas em segundo plano, (Anexo I).

12 Recordamos o Segundo Considerando da Declaração e Programa de Ação de Viena de 1993

${ }^{13}$ ROCHA, 2011, Op. cit, apontou como principais motivos das recentes revoluções árabes o aumento do fator educação, associado a um paralelo aumento dos problemas sociais, sobretudo considerando-se o incremento tecnológico e as possibilidade decorrentes da tecnologia da informação aplicadas à comunicação. Apontou ainda, que são os jovens (que sempre tem uma maior disposição para lutas e mudanças) os maiores usuários dessas tecnologias. 
construído a partir da "liberdade", no sentido de que, sendo todos livres, todos devem participar da formação da vontade do Estado, igualmente.

A democracia é vista em Kelsen, como um método de organização social onde o governo é exercido a partir das decisões majoritárias de uma assembléia garantidora de participação popular direta ou indireta (KELSEN, 2000, p. 140-142). Repousa então sobre o princípio da maioria, onde a relação maioria - minoria é regida pelo princípio da igualdade, que se desdobra no princípio da tolerância, também chamado de fraternidade. Desse modo, se todos em uma dada sociedade são iguais, suas opiniões e votos também são iguais, inclusive no sentido da importância, sendo irrelevante para determinar o grau dessa importância a qualidade da opinião ou voto - se filiada a maioria ou a minoria (KELSEN, 2000, p. 182-185). Nesse contexto, surge a função do parlamento, baseada em discursos e réplicas, argumentos e contra-argumentos, de converter as teses e as antíteses em sínteses. (KELSEN, 2000, p. 70).

É no exercício dessa função parlamentar - de mediar as vontades da maioria e da minoria - que encontramos a relação entre democracia e direitos humanos, que estávamos buscando em Kelsen:

Impedir o domínio de classe é o que o princípio majoritário - no âmbito do parlamentarismo tem condições de realizar. Já é característico que, na prática, ele se mostre compatível com a proteção da minoria. De fato, a existência da maioria pressupõem, por definição a existência de uma minoria e, por conseqüência, o direito da maioria pressupõem o direito à existência de uma minoria. Disto resulta não tanto a necessidade, mas principalmente a possibilidade de proteger a minoria contra a maioria. Esta proteção da minoria é a função essencial dos chamados direitos fundamentais, ou direitos do homem e do cidadão. (...) significa que o rol dos direitos fundamentais e das liberdades fundamentais se transforma, de instrumento de proteção do indivíduo contra o Estado, em instrumento de proteção da minoria (KELSEN, 2000, p. 67, 68).

Assim, na Democracia de Kelsen, os Direitos Fundamentais (Direitos

Humanos na versão universalista), assumem um papel negativo - invertendo com a democracia os papeis para eles previstos na maior parte dos dispositivos internacionais identificados na Seção I deste trabalho - um papel limitador da vontade das maiorias, impedindo que esta se imponha de maneira absoluta sobre as minorias, e isso, como forma de garantir a própria democracia.

Na obra "O que é a democracia?” de Alain Touraine a democracia é vista a partir de três dimensões que a compõem: respeito pelos direitos humanos, cidadania e representatividade dos dirigentes ${ }^{14}$. A representatividade dos governantes refere-se ao fato de

${ }^{14}$ Segundo Touraine " a autonomia dos componentes da democracia é tão grande que se pode falar das dimensões da democracia (...), cada uma dessas dimensões tende a opor-se as outras, ao mesmo tempo que pode se combinar com elas." 
que estes agentes políticos são meros representantes, instrumentos dos atores sociais, que por constituírem uma pluralidade, determinam o pluralismo da própria democracia. A cidadania está relacionada a um sentimento de pertencimento - os eleitores precisam considerar-se cidadãos, no sentido de interessarem-se pelo governo e identificarem-se com o que está sendo debatido ( TOURAINE, 1996, p. 43-44). Mas, é o dever de respeito aos direitos humanos fundamentais, que recebe o papel mais importante para Touraine. Serve como limite imposto ao próprio Estado, ganhando especial relevo e assumindo mesmo, a condição de princípio democrático e verdadeira condição indispensável para a existência da democracia, pois a própria "livre escolha" estaria ameaçada se o poder dos governantes não fosse limitado (TOURAINE, 1996, p. 56).

Por outro lado, Touraine não identifica a existência de um princípio mais geral que esses três elementos da democracia, e assim sendo, "o elo que os une e obriga a se combinar é apenas negativo: consiste precisamente na ausência de um princípio central de poder e legitimação"(TOURAINE,1996, p. 46).

\section{CONCLUSÕES}

Embora assim previsto em termos dogmáticos, não é inquestionável que os direitos humanos e a democracia sejam valores universais.

A título de Declarações, no âmbito interamericano, desde 1969, é perceptível essa pretensão, bem como também uma valoração transcendental da democracia, capaz de lhe colocar inclusive como vetor interpretativo dos direitos humanos.

No que se refere ao âmbito global, a declaração de aspiração universalista da democracia só se deu em 1993 após a derrocada do socialismo soviético. A Declaração de Viena de 1993 ainda apontou a interdependência e necessidade de reforço mútuo dos direitos humanos e da democracia, no entanto, a maioria das disposições contemporâneas, constantes de Instrumentos Internacionais, que de alguma forma relacionam democracia e direitos humanos, colocam a primeira como parte do suporte que autoriza alguma limitação dos segundos.

Rev. de Teorias da Democracia e Direitos Políticos | e-ISSN: 2525-9660 | Goiânia| v. 5 | n. 1 | p. 104-125 | Jan/Jun. 2019 
Em sentido oposto, Alain Touraine e Hans Kelsen, teorizam direitos humanos como espécie de garantes da democracia, precisando para tanto estabelecer limites em prol dela. Em Touraine os direitos humanos impõem limites ao próprio Estado, como forma de garantir que a escolha, realmente seja livre, e por via de consequiência, garantir a própria democracia; em Kelsen, cabe aos direitos humanos limitar a vontade das maiorias, como forma de impedir o domínio absoluto destas sobre as minorias, aperfeiçoando assim, a democracia.

A democracia funcionou historicamente, muitas vezes, inclusive em sua origem, como limitadora dos poderes públicos. Essa função muito se aproxima de diversas previsões constantes de alguns Instrumentos Internacionais que versam sobre direitos humanos. Isso milita em favor do reconhecimento, de no mínimo, indícios de direitos humanos, desde muito antes do século revolucionário, possibilitando inclusive falar-se, que em algum sentido, direitos humanos e democracia tiveram origem comum.

Há eventos históricos que parecem apontar para além de uma teorização universalista, por uma efetiva necessidade prática de universalização dos direitos humanos e que talvez, por força da interdependência histórica, filosófica e dogmática desses com a democracia, por arrasto, para o universalismo dela também. Dentre esses eventos, um há que, em virtude do vulto de sua dramaticidade histórica, prescinde de qualquer maior comprovação: a Segunda Grande Guerra Mundial.

\section{REFERÊNCIAS BIBLIOGRÁFICAS}

BENEVIDES, Maria Vitória de Mesquita. Democracia e Direitos Humanos reflexão para os jovens. Democracia e Direitos Humanos 2014. Disponível em: http://www.cchla.ufpb.br/redhbrasil/wp-content/uploads/2014/04/DEMOCRACIA-EDIREITOS-HUMANOS.pdf

BORGES, Alexandre Walmott. As Constituições latino-americanas: a caracterização a partir da dualidade constituições liberais e constituições sociais. In: BORGES, Alexandre Walmott; COELHO, Saulo de Oliveira Pinto. Interconstitucionalidade e Interdisciplinaridade: desafios, âmbitos e níveis de interação no mundo global. Uberlândia: LAECC, 2015, p. 85107 
BOUDERBALA, Sofia. Democracia, aspiração universal com as revoluções árabes. https://exame.abril.com.br/mundo/democracia-aspiracao-universal-com-as-revolucoesarabes/, acesso em 10/01/2019.

COELHO, Saulo de Oliveira Pinto; PEDRA, Cairo. Direitos Humanos entre Discurso e Ideologias: a plurivocidade semântica dos direitos fundamentais, a necessidade de crítica democrática permanente e o risco permanente de reviravolta autoritária. In: MACHADO; OLIVEIRA (orgs.). Direitos Fundamentais e Democracia. Florianópolis: Conpedi/Funjab, p. 173-192, 2013.

COELHO, Saulo de Oliveira Pinto. Reconhecimento, Experiência e Historicidade: considerações para uma compreensão dos Direitos Humano-Fundamentais como (In)variáveis Principiológicas do Direito nas sociedades democráticas contemporâneas. In: SOBREIRA FILHO; FARIAS; OLIVEIRA JR. (orgs.). Filosofia do Direito. Florianópolis: Conpedi/Funjab, p. 175-195, 2012

COELHO, Saulo de Oliveira Pinto. Para uma Crítica das Críticas aos Direitos Humanos: das críticas ao jushumanismo ao jushumanismo crítico. Revista Direitos Humanos e Efetividade. v.1, n. 2, Minas Gerais, p. 1-18, 2015.

COMPARATO, Fábio Konder. A Afirmação Histórica dos Direitos Humanos. $7^{\mathrm{a}}$ Ed - São Paulo: Saraiva, 2010.

FELIPPE, Márcio Sotelo. Os Instrumentos Internacionais de Proteção dos Direitos Humanos, Biblioteca Virtual da PGE-SP, 1996, disponível em http://www.pge.sp.gov.br/centrodeestudos/bibliotecavirtual/instrumentos/sumario.htm

KELSEN, Hans. Tradução de Ivone Castilho Benedetti, Jefferson Luiz Camargo, Marcelo Brandão Cipolla, Vera Barkow. A Democracia. $2^{a}$ Ed. São Paulo: Martins Fontes, 2000 .

LEMOS, Marcos Vieira de. Corte Interamericana de Direitos Humanos. In MENEZES, Wagner (Coordenador) Direito Internacional em Debate. Curitiba: íthala, 2008

OLIVEIRA, Samuel Antonio Merbach de . NORBERTO BOBBIO: teoria política e direitos humanos, Rev. Filos., v. 19, n. 25, p. 361-372, jul./dez. 2007

ROCHA, Maurício Santoro. As Revoltas Árabes e a Democratização do Magreb e do Oriente Médio. Revista Ética e Filosofia Política - No 13 - Volume 2 - Junho de 2011, pág. 110 a 124

SANTOS, Boaventura de Sousa. Por uma concepção multicultural de direitos humanos. Revista Crítica de Ciências Sociais, Nº 48, Junho de 1997

SOUSA, Fernando de. A democracia, é face política da globalização? Revista brasileira de política internacional. v.49 n.1 Brasília jan./jun. 2006 
TOURAINE, Alain. Tradução de Guilherme João de Freitas Teixeira. O que é a democracia? 2 Ed. Petrópolis: Vozes, 1996.

EIU Democracy Index 2017 - Infographics - The Economist, disponíve em

https://infographics.economist.com/2018/DemocracyIndex/

\begin{abstract}
ANEXO I
Dispositivos das Declarações Internacionais aprovadas e dos Tratados Internacionais ratificados pelo Brasil, que versam sobre Direitos Humanos e que se referem à Democracia
\end{abstract}

Nota: não há negrito em nenhum dos originais.

\title{
DECLARAÇÃO UNIVERSAL DOS DIREITOS HUMANOS (1948)
}

Artigo XXIX (...) 2. No exercício de seus direitos e liberdades, toda pessoa estará sujeita apenas às limitações determinadas pela lei, exclusivamente com o fim de assegurar o devido reconhecimento e respeito dos direitos e liberdades de outrem, e de satisfazer às justas exigências da moral, da ordem pública e do bem-estar de uma sociedade democrática.

\section{DECLARAÇÃO AMERICANA DOS DIREITOS E DEVERES DO HOMEM (1948)}

Artigo XXVIII. Os direitos do homem estão limitados pelos direitos do próximo, pela segurança de todos e pelas justas exigências do bem-estar geral e do desenvolvimento democrático.

\section{PACTO INTERNACIONAL DOS DIREITOS CIVIS E POLÍTICOS (1966)}

Artigo 14 - 1. Todas as pessoas são iguais perante os Tribunais e as Cortes de Justiça. Toda pessoa terá o direito de ser ouvida publicamente e com as devidas garantias por um Tribunal competente, independente e imparcial, estabelecido por lei, na apuração de qualquer acusação de caráter penal formulada contra ela ou na determinação de seus direitos e obrigações de caráter civil. A imprensa e o público poderão ser excluídos de parte ou da totalidade de um julgamento, quer por motivo de moral pública, ordem pública ou de segurança nacional em uma sociedade democrática, (...)

Artigo 21 - O direito de reunião pacífica será reconhecido. O exercício desse direito estará sujeito apenas às restrições previstas em lei e que se façam necessárias, em uma sociedade 
democrática, ao interesse da segurança nacional, da segurança ou ordem públicas, ou para proteger a saúde ou a moral públicas ou os direitos e as liberdades das demais pessoas.

Artigo $22-(\ldots)$ 1. Toda pessoa terá o direito de associar-se livremente a outras, inclusive o direito de constituir sindicatos e de a eles filiar-se, para proteção de seus interesses.

2. O exercício desse direito estará sujeito apenas às restrições previstas em lei e que se façam necessárias, em uma sociedade democrática, ao interesse da segurança nacional, da segurança e da ordem públicas, ou para proteger a saúde ou a moral públicas ou os direitos e as liberdades das demais pessoas. O presente artigo não impedirá que se submeta a restrições legais o exercício desses direitos por membros das forças armadas e da polícia.

PACTO INTERNACIONAL DOS DIREITOS ECONÔMICOS, SOCIAIS E CULTURAIS (1966)

Artigo $4^{\circ}$ - Os Estados-partes no presente Pacto reconhecem que, no exercício dos direitos assegurados em conformidade com o presente Pacto pelo Estado, este poderá submeter tais direitos unicamente às limitações estabelecidas em lei, somente na medida compatível com a natureza desses direitos e exclusivamente com o objetivo de favorecer o bem-estar geral em uma sociedade democrática.

Artigo $8^{\circ}$ - 1. Os Estados-partes no presente Pacto comprometem-se a garantir:

a) $\mathrm{O}$ direito de toda pessoa de fundar com outras sindicatos e de filiar-se ao sindicato de sua escolha, sujeitando-se unicamente aos estatutos da organização interessada, com o objetivo de promover e de proteger seus interesses econômicos e sociais. O exercício desse direito só poderá ser objeto das restrições previstas em lei e que sejam necessárias, em uma sociedade democrática, ao interesse da segurança nacional ou da ordem pública, ou para proteger os direitos e as liberdades alheias;

\section{(...)}

c) $\mathrm{O}$ direito dos sindicatos de exercer livremente suas atividades, sem quaisquer limitações além daquelas previstas em lei e que sejam necessárias, em uma sociedade democrática, ao interesse da segurança nacional ou da ordem pública, ou para proteger os direitos e as liberdades das demais pessoas;

CONVENÇÃO AMERICANA DE DIREITOS HUMANOS (1969) 
Preâmbulo, $1^{\circ}$ considerando: Reafirmando seu propósito de consolidar neste Continente, dentro do quadro das instituições democráticas, um regime de liberdade pessoal e de justiça social, fundado no respeito dos direitos humanos essenciais;

Artigo 15 - Direito de reunião

É reconhecido o direito de reunião pacífica e sem armas. O exercício desse direito só pode estar sujeito às restrições previstas em lei e que se façam necessárias, em uma sociedade democrática, ao interesse da segurança nacional, da segurança ou ordem públicas, ou para proteger a saúde ou a moral públicas ou os direitos e as liberdades das demais pessoas.

Artigo 16 - Liberdade de associação

1. Todas as pessoas têm o direito de associar-se livremente com fins ideológicos, religiosos, políticos, econômicos, trabalhistas, sociais, culturais, desportivos ou de qualquer outra natureza.

2. O exercício desse direito só pode estar sujeito às restrições previstas em lei e que se façam necessárias, em uma sociedade democrática, ao interesse da segurança nacional, da segurança e da ordem públicas, ou para proteger a saúde ou a moral públicas ou os direitos e as liberdades das demais pessoas.

Artigo 22 - Direito de circulação e de residência

(...)

3. O exercício dos direitos supracitados não pode ser restringido, senão em virtude de lei, na medida indispensável, em uma sociedade democrática, para prevenir infrações penais ou para proteger a segurança nacional, a segurança ou a ordem públicas, a moral ou a saúde públicas, ou os direitos e liberdades das demais pessoas.

\section{(...)}

\section{Artigo 29 - Normas de interpretação}

Nenhuma disposição da presente Convenção pode ser interpretada no sentido de:

c) excluir outros direitos e garantias que são inerentes ao ser humano ou que decorrem da forma democrática representativa de governo;

Artigo 32 - Correlação entre deveres e direitos

1. Toda pessoa tem deveres para com a família, a comunidade e a humanidade.

2. Os direitos de cada pessoa são limitados pelos direitos dos demais, pela segurança de todos e pelas justas exigências do bem comum, em uma sociedade democrática.

\section{CONVENÇÃO SOBRE OS DIREITOS DA CRIANÇA (1989)}

Artigo 15 - 1. Os Estados-partes reconhecem os direitos da criança à liberdade de associação e à liberdade de reunião pacífica. 
2. Nenhuma restrição poderá ser imposta ao exercício desses direitos, a não ser as que, em conformidade com a lei, forem necessárias em uma sociedade democrática, nos interesses da segurança nacional ou pública, ordem pública (ordre public), da proteção da saúde ou moral públicas, ou da proteção dos direitos e liberdades de outrem.

\section{DECLARAÇÃO E PROGRAMA DE AÇÃO DE VIENA (1993)}

Considerando as importantes mudanças em curso no cenário internacional e as aspirações de todos os povos por uma ordem internacional baseada nos princípios consagrados na Carta das Nações Unidas, incluindo a promoção dos direitos humanos e liberdades fundamentais de todas as pessoas e o respeito pelo princípio dos direitos iguais e autodeterminação dos povos em condições de paz, democracia, justiça, igualdade, Estados de Direito, pluralismo, desenvolvimento, melhores padrões de vida e solidariedade,

8. A democracia, o desenvolvimento e o respeito aos direitos humanos e liberdades fundamentais são conceitos interdependentes que se reforçam mutuamente. A democracia se baseia na vontade livremente expressa pelo povo de determinar seus próprios sistemas políticos, econômicos, sociais e culturais e em sua plena participação em todos os aspectos de suas vidas. Nesse contexto, a promoção e proteção dos direitos humanos e liberdades fundamentais, em níveis nacional e internacional, devem ser universais e incondicionais. A comunidade internacional deve apoiar o fortalecimento e a promoção de democracia e o desenvolvimento e respeito aos direitos humanos e liberdades fundamentais no mundo inteiro.

9. A Conferência Mundial sobre Direitos Humanos reafirma que os países menos desenvolvidos que optaram pelo processo de democratização e reformas econômicas, muitos dos quais situam-se na África, devem ter o apoio da comunidade internacional em sua transição para a democracia e o desenvolvimento econômico.

\section{DECLARAÇÃO DE PEQUIM ADOTADA PELA QUARTA CONFERÊNCIA} MUNDIAL SOBRE AS MULHERES: AÇÃO PARA IGUALDADE, DESENVOLVIMENTO E PAZ (1995)

15. A igualdade de direitos, oportunidades e acesso aos recursos, a distribuição equitativa das responsabilidades familiares entre homens e mulheres e a harmônica associação entre eles são 
fundamentais para seu próprio bem-estar e de suas famílias, como também para a consolidação da democracia;

ANEXO II

Quadro síntese das Normas Internacionais que expressamente relacionam Democracia e Direitos Humanos, em ordem cronológica.

\begin{tabular}{|c|c|c|}
\hline $\begin{array}{l}\text { INSTRUMENTO } \\
\text { INTERNACIONAL }\end{array}$ & DISPOSITI & SÍNTESE DO CONTEÚDO \\
\hline DECLARAÇÃO & \multirow[b]{2}{*}{ Art. XXIX. } & \multirow[b]{2}{*}{ RIPD } \\
\hline $\begin{array}{lr}\text { UNIVERSAL } & \text { DOS } \\
\text { DIREITOS } & \text { HUMANOS } \\
(1948) & \end{array}$ & & \\
\hline DECLARAÇÃO & \multirow[b]{2}{*}{ Artigo } & \multirow[b]{2}{*}{ RIPD } \\
\hline $\begin{array}{l}\text { AMERICANA } \\
\text { DIREITOS E DEV } \\
\text { DO HOMEM (1948) }\end{array}$ & & \\
\hline \multirow{3}{*}{$\begin{array}{l}\text { PACTO } \\
\text { INTERNACIONAL } \\
\text { DOS } \\
\text { DIREITOS CIVIS } \\
\text { POLÍTICOS (1966) }\end{array}$} & Artigo & RIPD \\
\hline & Artigo 21; & RIPD \\
\hline & Artigo $22-$ & RIPD \\
\hline \begin{tabular}{l}
\multicolumn{1}{c}{ PACTO } \\
INTERNACIONAL DOS \\
DIREITOS \\
ECONÔMICOS, SOCIAIS \\
E CULTURAIS (1966)
\end{tabular} & $\begin{array}{l}\text { Artigo } 4^{\circ} \\
\text { Artigo } 8^{\circ}- \\
\text { 1.a) } \\
\text { 1.c) Artigo } 8^{\circ}-\end{array}$ & RIPD \\
\hline CONVENÇÃO & $1^{\circ}$ & Reafirmando seu propósito \\
\hline $\begin{array}{lr}\text { AMERICANA } & \text { DE } \\
\text { DIREITOS } & \text { HUMANOS }\end{array}$ & Considerando & $\begin{array}{l}\text { de consolidar neste Continente, dentro } \\
\text { do quadro das instituições }\end{array}$ \\
\hline
\end{tabular}

Rev. de Teorias da Democracia e Direitos Políticos | e-ISSN: 2525-9660 | Goiânia| v. 5 | n. 1 | p. 104-125| 


\begin{tabular}{|c|c|c|}
\hline \multirow[t]{6}{*}{ (1969) } & & $\begin{array}{l}\text { democráticas, um regime de liberdade } \\
\text { pessoal e de justiça social, fundado no } \\
\text { respeito dos direitos humanos } \\
\text { essenciais; }\end{array}$ \\
\hline & Art. 15 & RIPD \\
\hline & Art. 16.2 & RIPD \\
\hline & Art. 22.3 & RIPD \\
\hline & Art. 29. c) & $\begin{array}{l}\text { Nenhuma disposição da } \\
\text { presente Convenção pode ser } \\
\text { interpretada no sentido de: excluir } \\
\text { outros direitos e garantias que são } \\
\text { inerentes ao ser humano ou que } \\
\text { decorrem da forma democrática } \\
\text { representativa de governo; }\end{array}$ \\
\hline & Art. 32.2 & RIPD \\
\hline $\begin{array}{l}\text { CONVENÇÃO } \\
\text { SOBRE OS DIREITOS DA } \\
\text { CRIANÇA (1989) }\end{array}$ & Artigo 15 & RIPD \\
\hline \multirow[b]{2}{*}{$\begin{array}{l}\text { DECLARAÇÃO E } \\
\text { PROGRAMA DE AÇÃO } \\
\text { DE VIENA (1993) }\end{array}$} & $\begin{array}{c}2^{\circ} \\
\text { Considerando; }\end{array}$ & $\begin{array}{l}\text { Considera a democracia } \\
\text { uma aspiração universal. }\end{array}$ \\
\hline & I.8; & $\begin{array}{l}\text { Interdependência e reforço } \\
\text { mutuo entre democracia e direitos } \\
\text { humanos / Fundamentação da } \\
\text { democracia na liberdade } \\
\text { (autodeterminação) / A comunidade } \\
\text { internacional deve apoiar o } \\
\text { fortalecimento e a promoção de }\end{array}$ \\
\hline
\end{tabular}




\begin{tabular}{|c|c|l|}
\hline & I.9 & $\begin{array}{l}\text { democracia e o desenvolvimento e } \\
\text { respeito aos direitos humanos. } \\
\text { Refere-se a necessidade de } \\
\text { apoio da comunidade internacional aos } \\
\text { países subdesenvolvidos em sua } \\
\text { transição para a democracia. }\end{array}$ \\
\hline DECLARAÇÃO & 15 & $\begin{array}{l}\text { Prevê a igualdade de direitos } \\
\text { como fundamental para a consolidação } \\
\text { democrática. }\end{array}$ \\
\hline
\end{tabular}

Fonte: Anexo I 